\title{
Association of Comorbidities With Pneumonia and Death Among COVID-19 Patients in Mexico: A Nationwide Cross-sectional Study
}

\author{
Akram Hernández-Vásquez ${ }^{1}$, Diego Azañedo ${ }^{2}$, Rodrigo Vargas-Fernández ${ }^{3}$, Guido Bendezu-Quispe ${ }^{4}$ \\ 'Universidad San Ignacio de Loyola, Vicerrectorado de Investigación, Centro de Excelencia en Investigaciones Económicas y Sociales en Salud, Lima, \\ Peru; ${ }^{2}$ Universidad Católica los Ángeles de Chimbote, Instituto de Investigación, Chimbote, Peru; ${ }^{3}$ Universidad Científica del Sur, Lima, Peru; \\ ${ }^{4}$ Universidad San Ignacio de Loyola, Vicerrectorado de Investigación, Unidad de Investigación para la Generación y Síntesis de Evidencias en Salud, \\ Lima, Peru
}

Objectives: The goal of this study was to identify chronic conditions and multimorbidity patterns in patients with coronavirus disease 2019 (COVID-19) and to examine their associations with pneumonia and death.

Methods: This cross-sectional study analyzed the official data of COVID-19 patients in Mexico through May 18, 2020 (released by the Secretaría de Salud de México). Adjusted logistic regression models were applied to assess the associations of comorbidities with pneumonia and death. The marginal effects were estimated, and the probability of pneumonia or death according to the number of comorbidities was graphed for each year of age.

Results: Of the 51053 COVID-19 patients enrolled in the final analysis, 27667 (54.2\%) had no chronic conditions, while 13652 (26.7\%), 6518 (12.8\%) and 3216 (6.3\%) were reported to have 1, 2, and 3 or more simultaneous conditions, respectively. Overall, a significant incremental gradient was observed for the association between multimorbidity and pneumonia $(p<0.001)$; for 2 chronic conditions, the adjusted odds ratio (aOR) was 2.07 (95\% confidence interval [Cl], 1.95 to 2.20 ), and for $\geq 3$ conditions, the aOR was $2.40(95 \% \mathrm{Cl}$, 2.22 to 2.60). A significant incremental gradient was also found for the relationship between multimorbidity and death $(p<0.001)$; an aOR of 2.51 ( $95 \% \mathrm{Cl}, 2.30$ to 2.73) was found for 2 chronic conditions and an aOR of 3.49 ( $95 \% \mathrm{Cl}, 3.15$ to 3.86 ) for $\geq 3$ conditions.

Conclusions: Underlying chronic conditions and multimorbidity are associated with pneumonia and death in Mexican COVID-19 patients. Future investigation is necessary to clarify the pathophysiological processes behind this association, given the high burden of chronic diseases in various countries, including Mexico.

Key words: Comorbidity, COVID-19, Multimorbidity, Severe acute respiratory syndrome coronavirus 2, Mexico

Received: May 10, 2020 Accepted: May 27, 2020

Corresponding author: Akram Hernández-Vásquez, MD Universidad San Ignacio de Loyola, Vicerrectorado de Investigación, Centro de Excelencia en Investigaciones Económicas y Sociales en Salud, 550 La Fontana Avenue, La Molina 00012, Lima, Peru E-mail: ahernandez.v@usil.edu.pe

This is an Open Access article distributed under the terms of the Creative Commons Attribution Non-Commercial License (https://creativecommons.org/licenses/by$\mathrm{nc} / 4.0 / /$ which permits unrestricted non-commercial use, distribution, and reproduction in any medium, provided the original work is properly cited.

\section{INTRODUCTION}

Coronavirus disease 2019 (COVID-19) is a recently-discovered infectious disease caused by the severe acute respiratory syndrome coronavirus 2 (SARS-CoV-2) virus that has quickly become a global pandemic. As of the writing of this report, more than 3 million cases and nearly 250000 deaths have been documented. However, the epidemiology of the disease 
is still being studied, and much more information is required to establish adequate measures for its prevention and control, especially among patients vulnerable to severe disease (pneumonia) or death [1].

Several studies have demonstrated higher frequencies of severe cases and mortality among COVID-19 patients with underlying comorbidities, such as diabetes, high blood pressure (HBP), obesity, and cardiovascular disease (CVD), relative to patients without comorbidities $[2,3]$. Although the causal mechanisms by which chronic conditions increase the risk of COVID-19 severity and mortality are still being studied, it has been postulated that patients with HBP and diabetes have an increased susceptibility of severe SARS-CoV-2 infection $[4,5]$. It has also been proposed that SARS-CoV-2 infection may cause or worsen endotheliitis, which can further affect the condition of people with previous endothelial dysfunction, such as those with obesity, diabetes, HBP, and other CVDs [5]. This raises the question of how multimorbidity - the presence of 2 or more chronic comorbidities-may influence disease severity and mortality in patients with SARS-CoV-2 infection.

Mexico has one of the highest COVID-19 mortality rates among Latin American countries. As of May 18, 2020, more than 20000 confirmed cases and 2154 deaths attributed to COVID-19 had been reported in Mexico [1]. The potential associations of multimorbidity with disease severity and mortality in COVID-19 patients have received special attention in Mexico, as it is one of the Latin American countries with the highest prevalence of chronic conditions; $19.0-25.5 \%$ of Mexican adults have HBP, $10.0 \%$ have diabetes, and $28.0 \%$ are obese $[6,7]$. To date, only 1 peer-reviewed study, conducted in China, has reported a higher combined risk of admission to intensive care, intubation, or death in patients with multimorbidity compared to those without multimorbidity [8]. However, this association has not been studied in Latin America, and pneumonia and death have not been considered as separate outcomes.

The epidemiological surveillance system of the Secretaría de Salud de México collects information regarding the characteristics and comorbidities of diagnosed COVID-19 cases, as well as their clinical course and outcomes. The government of Mexico has released these data. In this study, we aimed to identify the chronic conditions and multimorbidity patterns present among COVID-19 patients and to examine their associations with pneumonia and death. Our results could help facilitate better understanding and decision-making regarding the identification of groups at relatively high risk of severe illness and death due to
COVID-19 and the implementation of preventative measures affecting these groups.

\section{METHODS}

\section{Study Design and Data Source}

A cross-sectional study was performed to analyze the publicly available data of patients with COVID-19 diagnosed via reverse transcription-polymerase chain reaction (RT-PCR). These data were released by the Secretaría de Salud de México and covered the period ending on May 18, 2020. Socio-demographic and medical data (regarding date of disease onset, disease duration, epidemiological profile, presence of chronic conditions, molecular diagnostic test result, and vital status), were collected by physicians using an epidemiological COVID-19 case report form in suspected COVID-19 patients. These data were systematized using an epidemiological surveillance system and are available at https://www.gob.mx/salud/documentos/datos-abiertos-152127.

\section{Study Variables}

The dependent variables were pneumonia and death in patients with COVID-19. Eight comorbidities were included as independent variables: HBP, diabetes, obesity, asthma, immunosuppression, other CVDs, chronic obstructive pulmonary disease (COPD), and chronic kidney disease. The chronic conditions included in the analysis corresponded to the conditions reported as associated with COVID-19 in the literature [9-15] and the availability of the relevant information in the patient data. A simple count of the 8 comorbidities was used to classify participants into 4 categories: no comorbidity, 1 comorbidity, 2 comorbidities, or 3 or more comorbidities. Likewise, the 3 most frequent comorbidities (HBP, diabetes, and obesity) were classified into dyads. The presence of $\geq 2$ of the 8 reported comorbidities was considered to indicate multimorbidity.

\section{Statistical Analysis}

The variables of interest were presented as frequencies and percentages for the categorical variables and as means and standard deviations for the continuous variables. The frequencies of pneumonia and death were presented according to the characteristics and comorbidities evaluated and stratified by sex. Simple logistic regression models were applied to measure the associations of the independent variables with pneumonia and death in patients with COVID-19. The chronic con- 
ditions that were found to be associated with pneumonia or death $(p<0.05)$ in the simple logistic regression analysis were included in two adjusted logistic regression models. The covariables included in the adjusted models were age (continuous), gender (men/women), and smoking status (yes/no). The results were expressed as odds ratios (ORs) and adjusted odds ratios (aORs) with $95 \%$ confidence intervals ( $\mathrm{Cls}$ ) for both models. Based on the adjusted models, the marginal effects were estimated along with their $95 \% \mathrm{Cl}$, and the probabilities of pneumonia and death according to the number of comorbidities for each year of age were graphed.

Statistical analysis was performed using Stata version 14 (StataCorp., College Station, TX, USA). For all analyses, a $p$-value $<0.05$ was considered statistically significant.

\section{Ethics Statement}

As an analysis of secondary data, this study did not require the approval of an institutional ethics committee. The data are publicly available on the platform of the Secretaría de Salud de México under the Mexican open data policy intended to facilitate the access, use, reuse, and redistribution of information.

\section{RESULTS}

Complete data regarding the study variables were available for 51053 patients with COVID-19, and these patients were included in the analysis. A total of 580 patients were excluded due to incomplete data. Of the included patients, 29422 were men $(57.6 \%)$. The overall mean age was $46.6 \pm 15.8$ years (men, $47.1 \pm 15.7$ years; women, $45.8 \pm 16.0$ years). The mean disease duration was $4.2 \pm 3.3$ days. A total of 14684 (28.8\%) patients presented with pneumonia (men, $32.5 \%$; women, 23.7\%).

Regarding the presence of chronic conditions, 27667 (54.2\%) of the participants had no comorbidities, while 13652 (26.7\%) presented 1 chronic condition. Multimorbidity was present in 9734 (19.1\%) of the patients, with the presence of $2(n=6518$, $12.8 \%)$ and $3(n=2490,4.9 \%)$ comorbidities being the most common. The largest number of simultaneous chronic conditions was 8 (14 patients) (Table 1).

The results included 5233 (10.3\%) deaths (men, 12.1\%; women, $7.7 \%$ ), with a mean time from disease onset to death of $10.6 \pm 6.5$ days (Table 1). Regarding age group, pneumonia was reported in more than $50 \%$ of the people in the $65-74$ (50.3\%), 75-84 (53.7\%), and 85 or older (51.4\%) age groups,
Table 1. Characteristics of the Mexican population with coronavirus disease 2019 (COVID-19)

\begin{tabular}{|c|c|c|c|}
\hline Characteristics & $\begin{array}{c}\text { Overall } \\
(n=51053)\end{array}$ & $\begin{array}{c}\text { Men } \\
(n=29 \text { 422) }\end{array}$ & $\begin{array}{c}\text { Women } \\
(n=21 \text { 631) }\end{array}$ \\
\hline Age (y) & $46.6 \pm 15.8$ & $47.1 \pm 15.7$ & $45.8 \pm 16.0$ \\
\hline Duration of illness & $4.2 \pm 3.3$ & $4.2 \pm 3.3$ & $4.1 \pm 3.3$ \\
\hline \multicolumn{4}{|l|}{ HBP } \\
\hline No & 39963 (78.3) & 23147 (78.7) & $16816(77.7)$ \\
\hline Yes & $11090(21.7)$ & $6275(21.3)$ & $4815(22.3)$ \\
\hline \multicolumn{4}{|l|}{ Diabetes } \\
\hline No & $41667(81.6)$ & 23976 (81.5) & 17691 (81.8) \\
\hline Yes & 9386 (18.4) & $5446(18.5)$ & 3940 (18.2) \\
\hline \multicolumn{4}{|l|}{ Obesity } \\
\hline No & 40412 (79.2) & 23625 (80.3) & $16787(77.6)$ \\
\hline Yes & 10641 (20.8) & $5797(19.7)$ & $4844(22.4)$ \\
\hline \multicolumn{4}{|l|}{ Asthma } \\
\hline No & $49463(96.9)$ & $28752(97.7)$ & 20711 (95.7) \\
\hline Yes & $1590(3.1)$ & $670(2.3)$ & $920(4.3)$ \\
\hline \multicolumn{4}{|l|}{ Immunosuppression } \\
\hline No & 50212 (98.4) & 28987 (98.5) & 21225 (98.1) \\
\hline Yes & $841(1.6)$ & $435(1.5)$ & $406(1.9)$ \\
\hline \multicolumn{4}{|l|}{ Other CVD } \\
\hline No & 49682 (97.3) & 28628 (97.3) & 21054 (97.3) \\
\hline Yes & $1371(2.7)$ & 794 (2.7) & $577(2.7)$ \\
\hline \multicolumn{4}{|l|}{ COPD } \\
\hline No & 49934 (97.8) & 28815 (97.9) & $21119(97.6)$ \\
\hline Yes & $1119(2.2)$ & $607(2.1)$ & $512(2.4)$ \\
\hline \multicolumn{4}{|c|}{ Chronic kidney disease } \\
\hline No & 49795 (97.5) & 28662 (97.4) & $21133(97.7)$ \\
\hline Yes & $1258(2.5)$ & $760(2.6)$ & $498(2.3)$ \\
\hline \multicolumn{4}{|l|}{ HBP and diabetes } \\
\hline No & 35519 (69.6) & 20435 (69.5) & 15084 (69.7) \\
\hline Yes & $15534(30.4)$ & $8987(30.5)$ & $6547(30.3)$ \\
\hline \multicolumn{4}{|l|}{ HBP and obesity } \\
\hline No & 32874 (64.4) & 19187 (65.2) & 13687 (63.3) \\
\hline Yes & $18179(35.6)$ & 10235 (34.8) & $7944(36.7)$ \\
\hline \multicolumn{4}{|c|}{ Diabetes and obesity } \\
\hline No & $33769(66.1)$ & $19546(66.4)$ & $14223(65.8)$ \\
\hline Yes & 17284 (33.9) & 9876 (33.6) & 7408 (34.2) \\
\hline \multicolumn{4}{|l|}{ Smoking } \\
\hline No & 46715 (91.5) & 26232 (89.2) & 20483 (94.7) \\
\hline Yes & 4338 (8.5) & $3190(10.8)$ & $1148(5.3)$ \\
\hline \multicolumn{4}{|l|}{ Pneumonia } \\
\hline No & $36369(71.2)$ & $19857(67.5)$ & $16512(76.3)$ \\
\hline Yes & $14684(28.8)$ & 9565 (32.5) & $5119(23.7)$ \\
\hline \multicolumn{4}{|l|}{ Death } \\
\hline No & 45820 (89.7) & 25862 (87.9) & 19958 (92.3) \\
\hline Yes & 5233 (10.3) & $3560(12.1)$ & $1673(7.7)$ \\
\hline
\end{tabular}


Table 1. Continued from the previous page

\begin{tabular}{lccr}
\hline Characteristics & $\begin{array}{c}\text { Overall } \\
\text { (n=51 053) }\end{array}$ & $\begin{array}{c}\text { Men } \\
\text { (n=29 422) }\end{array}$ & $\begin{array}{c}\text { Women } \\
\text { (n=21 631) }\end{array}$ \\
\hline $\begin{array}{l}\text { Time from disease onset } \\
\text { to death }\end{array}$ & $10.6 \pm 6.5$ & $10.8 \pm 6.5$ & $10.2 \pm 6.5$ \\
$\begin{array}{l}\text { Comorbidities } \\
0\end{array}$ & $27667(54.2)$ & $16068(54.6)$ & $11599(53.6)$ \\
1 & $13652(26.7)$ & $7993(27.2)$ & $5659(26.2)$ \\
2 & $6518(12.8)$ & $3725(12.7)$ & $2793(12.9)$ \\
3 & $2490(4.9)$ & $1305(4.4)$ & $1185(5.5)$ \\
4 & $572(1.1)$ & $263(0.9)$ & $309(1.4)$ \\
5 & $109(0.2)$ & $49(0.2)$ & $60(0.3)$ \\
6 & $24(0.0)$ & $9(0.0)$ & $15(0.1)$ \\
7 & $7(0.0)$ & $5(0.0)$ & $2(0.0)$ \\
8 & $14(0.0)$ & $5(0.0)$ & $9(0.0)$ \\
Multimorbidity & & & \\
0 & $27667(54.2)$ & $16068(54.6)$ & $11599(53.6)$ \\
1 & $13652(26.7)$ & $7993(27.2)$ & $5659(26.2)$ \\
2 & $6518(12.8)$ & $3725(12.7)$ & $2793(12.9)$ \\
$\geq 3$ & $3216(6.3)$ & $1636(5.6)$ & $1580(7.3)$ \\
\hline
\end{tabular}

Values are presented as number (\%) or mean \pm standard deviation. HBP, high blood pressure; CVD, cardiovascular disease; COPD, chronic obstructive pulmonary disease.

while the greatest frequencies of death were found in the 65$74(27.1 \%), 75-84(29.1 \%)$, and 85 or older (31.3\%) age groups (Table 2). In the adjusted logistic regression model, across the entire study population, it was found that chronic conditions such as HBP, diabetes, obesity, immunosuppression, other CVDs, COPD, and chronic kidney disease were associated with an increased risk of pneumonia. In men, other CVDs and COPD were not found to be associated with pneumonia. Likewise, across the study population, chronic conditions such as HBP, diabetes, obesity, immunosuppression, other CVDs, COPD, and chronic kidney disease were associated with an increased probability of death (Table 3).

A significant incremental gradient was observed for the association between multimorbidity and pneumonia in the general population ( $p<0.001)$, with the presence of 1 (aOR, 1.68; $95 \% \mathrm{Cl}, 1.60$ to 1.77 ), 2 (aOR, 2.07; $95 \% \mathrm{Cl}, 1.95$ to 2.20 ), and 3 or more chronic conditions (aOR, $2.40 ; 95 \% \mathrm{Cl}, 2.22$ to 2.60 ) associated with a progressively increasing probability of this outcome. Likewise, across the study population, a significant incremental gradient $(p<0.001)$ was found for the relationship between multimorbidity and death, in which the presence of 1 (aOR, 1.89; $95 \% \mathrm{Cl}, 1.75$ to 2.04), 2 (aOR, 2.51; $95 \% \mathrm{Cl}, 2.30$ to 2.73), and 3 or more chronic conditions $(\mathrm{aOR}, 3.49 ; 95 \% \mathrm{Cl}$,
Table 2. Frequencies of pneumonia and death in the Mexican population with coronavirus disease 2019 (COVID-19) according to age group

\begin{tabular}{lccc}
\hline Characteristics & Overall & Men & Women \\
\hline Pneumonia & & & \\
Total (n) & 14684 & 9565 & 5119 \\
$0-19$ & $115(9.5)$ & $70(11.1)$ & $45(7.7)$ \\
$20-44$ & $3727(16.3)$ & $2477(19.5)$ & $1250(12.4)$ \\
$45-54$ & $3733(32.2)$ & $2537(37.0)$ & $1196(25.2)$ \\
$55-64$ & $3496(41.9)$ & $2250(45.3)$ & $1246(37.0)$ \\
$65-74$ & $2242(50.3)$ & $1425(52.0)$ & $817(47.6)$ \\
$75-84$ & $1087(53.7)$ & $647(54.5)$ & $440(52.5)$ \\
$\geq 85$ & $284(51.4)$ & $159(54.3)$ & $125(48.1)$ \\
Deaths & & & \\
Total (n) & 5233 & 3560 & 1673 \\
$0-19$ & $20(1.6)$ & $13(2.1)$ & $7(1.2)$ \\
$20-44$ & $708(3.1)$ & $512(4.0)$ & $196(1.9)$ \\
$45-54$ & $1161(10.0)$ & $845(12.3)$ & $316(6.7)$ \\
$55-64$ & $1374(16.5)$ & $928(18.7)$ & $446(13.3)$ \\
$65-74$ & $1207(27.1)$ & $798(29.1)$ & $409(23.8)$ \\
$75-84$ & $590(29.1)$ & $357(30.1)$ & $233(27.8)$ \\
$\geq 85$ & $173(31.3)$ & $107(36.5)$ & $66(25.4)$ \\
\hline
\end{tabular}

Values are presented as number ( $\%$ of the row).

3.15 to 3.86 ) were associated with an increased probability of death among the patients. These gradients demonstrating higher probabilities of pneumonia and death in patients with more chronic conditions were also present in both men and women and were statistically significant (Table 4).

Figure 1 shows the marginal effects of age and number of comorbidities on the probabilities of pneumonia and death. The probabilities of both pneumonia and death increased with the number of comorbidities and age.

\section{DISCUSSION}

In this study, we sought to identify patterns of chronic conditions and multimorbidity and to evaluate their associations with pneumonia and death in Mexican patients with COVID-19. Chronic conditions such as HBP, diabetes, obesity, other CVDs, and chronic kidney disease were found to increase the likelihood of pneumonia. Likewise, HBP, diabetes, obesity, immunosuppression, COPD, and chronic kidney disease increased the probability of death in patients with COVID-19. Regarding multimorbidity, a greater number of chronic conditions was found to be associated with an increased probability of death or pneumonia among the study sample. 
Table 3. Associations of chronic conditions with pneumonia and death in the Mexican population with coronavirus disease 2019 (COVID-19)

\begin{tabular}{|c|c|c|c|c|}
\hline \multirow{2}{*}{ Chronic conditions } & \multicolumn{2}{|c|}{ Pneumonia } & \multicolumn{2}{|c|}{ Death } \\
\hline & OR $(95 \% \mathrm{CI})$ & aOR $(95 \% \mathrm{CI})^{1}$ & OR (95\% CI) & aOR $\left(95 \%\right.$ Cl) ${ }^{1}$ \\
\hline \multicolumn{5}{|l|}{ Overall } \\
\hline HBP & $2.41(2.31,2.52)^{*}$ & $1.47(1.40,1.54)^{*}$ & $3.15(2.97,3.34)^{*}$ & $1.67(1.57,1.79)^{*}$ \\
\hline Diabetes & $2.93(2.79,3.06)^{*}$ & $1.94(1.84,2.04)^{*}$ & $3.34(3.14,3.55)^{*}$ & $2.00(1.87,2.13)^{*}$ \\
\hline Obesity & $1.47(1.40,1.54)^{*}$ & $1.49(1.42,1.56)^{*}$ & $1.49(1.40,1.59)^{*}$ & $1.62(1.52,1.74)^{*}$ \\
\hline Asthma & $0.74(0.66,0.83)^{*}$ & $0.91(0.80,1.03)$ & $0.75(0.63,0.91)^{*}$ & $1.02(0.84,1.23)$ \\
\hline Immunosuppression & $1.91(1.67,2.20)^{*}$ & $1.71(1.48,1.98)^{*}$ & $2.35(1.98,2.78)^{*}$ & $1.99(1.66,2.38)^{*}$ \\
\hline Other CVD & $2.08(1.87,2.32)^{*}$ & $1.23(1.10,1.38)^{*}$ & $2.64(2.32,3.01)^{*}$ & $1.34(1.17,1.55)^{*}$ \\
\hline COPD & $2.62(2.32,2.95)^{*}$ & $1.30(1.15,1.48)^{*}$ & $3.81(3.34,4.34)^{*}$ & $1.62(1.40,1.87)^{*}$ \\
\hline Chronic kidney disease & $2.75(2.46,3.08)^{*}$ & $2.01(1.78,2.26)^{*}$ & $4.37(3.87,4.94)^{*}$ & $3.08(2.70,3.51)^{*}$ \\
\hline HBP and diabetes & $2.91(2.80,3.03)^{*}$ & $1.84(1.76,1.92)^{*}$ & $3.69(3.48,3.92)^{*}$ & $2.00(1.87,2.13)^{*}$ \\
\hline HBP and obesity & $2.11(2.03,2.20)^{*}$ & $1.57(1.50,1.64)^{*}$ & $2.68(2.53,2.84)^{*}$ & $1.83(1.72,1.95)^{*}$ \\
\hline Diabetes and obesity & $2.30(2.21,2.39)^{*}$ & $1.83(1.75,1.91)^{*}$ & $2.71(2.56,2.88)^{*}$ & $2.08(1.96,2.21)^{*}$ \\
\hline \multicolumn{5}{|l|}{ Men } \\
\hline HBP & $2.13(2.01 .2 .25)^{*}$ & $1.34(1.26,1.43)^{*}$ & $2.67(2.47,2.87)^{*}$ & $1.48(1.37,1.61)^{*}$ \\
\hline Diabetes & $2.59(2.44,2.75)^{*}$ & $1.76(1.65,1.88)^{*}$ & $2.84(2.63,3.07)^{*}$ & $1.76(1.62,1.91)^{*}$ \\
\hline Obesity & $1.36(1.28,1.44)^{*}$ & $1.42(1.34,1.51)^{*}$ & $1.36(1.26,1.48)^{*}$ & $1.55(1.42,1.69)^{*}$ \\
\hline Asthma & $0.74(0.62,0.88)^{*}$ & $0.91(0.76,1.09)$ & $0.72(0.55,0.94)^{*}$ & $0.96(0.73,1.27)$ \\
\hline Immunosuppression & $1.73(1.43,2.10)^{*}$ & $1.48(1.21,1.81)^{*}$ & $2.29(1.83,2.87)^{*}$ & $1.85(1.46,2.36)^{*}$ \\
\hline Other CVDs & $1.82(1.58,2.09)^{*}$ & $1.11(0.95,1.29)$ & $2.32(1.97,2.75)^{*}$ & $1.23(1.03,1.47)^{*}$ \\
\hline COPD & $2.12(1.80,2.49)^{*}$ & $1.09(0.92,1.29)$ & $3.28(2.75,3.91)^{*}$ & $1.46(1.20,1.76)^{*}$ \\
\hline Chronic kidney disease & $2.43(2.10,2.81)^{*}$ & $1.84(1.58,2.15)^{*}$ & $3.80(3.26,4.44)^{*}$ & $2.79(2.36,3.29)^{*}$ \\
\hline HBP and diabetes & $2.52(2.39,2.66)^{*}$ & $1.64(1.55,1.74)^{*}$ & $3.04(2.83,3.26)^{*}$ & $1.72(1.59,1.86)^{*}$ \\
\hline HBP and obesity & $1.89(1.80,1.99)^{*}$ & $1.46(1.38,1.54)^{*}$ & $2.34(2.18,2.51)^{*}$ & $1.68(1.55,1.81)^{*}$ \\
\hline Diabetes and obesity & $2.06(1.96,2.17)^{*}$ & $1.69(1.60,1.78)^{*}$ & $2.35(2.19,2.52)^{*}$ & $1.88(1.74,2.02)^{*}$ \\
\hline \multicolumn{5}{|l|}{ Women } \\
\hline $\mathrm{HBP}$ & $3.03(2.83,3.25)^{*}$ & $1.67(1.54,1.80)^{* * *}$ & $4.51(4.07,4.99)^{*}$ & $2.11(1.88,2.36)^{*}$ \\
\hline Diabetes & $3.60(3.34,3.87)^{*}$ & $2.23(2.06,2.41)^{*}$ & $4.60(4.15,5.11)^{*}$ & $2.52(2.25,2.81)^{*}$ \\
\hline Obesity & $1.74(1.62,1.86)^{*}$ & $1.57(1.46,1.70)^{*}$ & $1.86(1.67,2.07)^{*}$ & $1.73(1.55,1.94)^{*}$ \\
\hline Asthma & $0.84(0.72,0.99)^{*}$ & $0.91(0.77,1.08)$ & $0.92(0.71,1.19)$ & Not include \\
\hline Immunosuppression & $2.30(1.88,2.81)^{*}$ & $2.01(1.62,2.49)^{*}$ & $2.73(2.43,3.07)^{*}$ & $1.99(1.76,2.24)^{*}$ \\
\hline Other CVDs & $2.56(2.16,3.03)^{*}$ & $1.42(1.19,1.71)^{*}$ & $3.33(2.71,4.10)^{*}$ & $1.53(1.23,1.92)^{*}$ \\
\hline COPD & $3.57(2.99,4.25)^{*}$ & $1.58(1.31,1.91)^{*}$ & $5.01(4.11,6.12)^{*}$ & $1.83(1.47,2.27)^{*}$ \\
\hline Chronic kidney disease & $3.31(2.77,3.96)^{*}$ & $2.28(1.89,2.76)^{*}$ & $5.55(4.55,6.77)^{*}$ & $3.63(2.93,4.49)^{*}$ \\
\hline HBP and diabetes & $3.75(3.52,4.01)^{*}$ & $2.21(2.05,2.38)^{*}$ & $5.72(5.14,6.37)^{*}$ & $2.77(2.47,3.12)^{*}$ \\
\hline HBP and obesity & $2.64(2.47,2.81)^{*}$ & $1.75(1.64,1.88)^{*}$ & $3.78(3.40,4.20)^{*}$ & $2.19(1.96,2.45)^{*}$ \\
\hline Diabetes and obesity & $2.82(2.65,3.01)^{*}$ & $2.07(1.93,2.21)^{*}$ & $3.79(3.42,4.21)^{*}$ & $2.57(2.31,2.87)^{*}$ \\
\hline
\end{tabular}

$\mathrm{OR}$, odds ratio; $\mathrm{Cl}$, confidence interval; aOR, adjusted odds ratio; HBP, high blood pressure; CVD, cardiovascular disease; COPD, chronic obstructive pulmonary disease.

${ }^{1}$ Adjusted analysis by age, sex, and smoking status in overall population (by age and smoking status in men and women).

${ }^{*} p<0.05$.

In the present study, an association was found between chronic conditions and pneumonia in patients with COVID-19. An early report from Wuhan, China, noted that about half of a sample of patients who were hospitalized for SARS-CoV-2 pneumonia had an additional medical condition. The most common comorbidities were HBP, diabetes, CVDs, and malignancies, which (except for malignancies) coincide with the most frequent conditions found in the Mexican population 
Table 4. Associations of multimorbidity with pneumonia and death in the Mexican population with coronavirus disease 2019 (COVID-19)

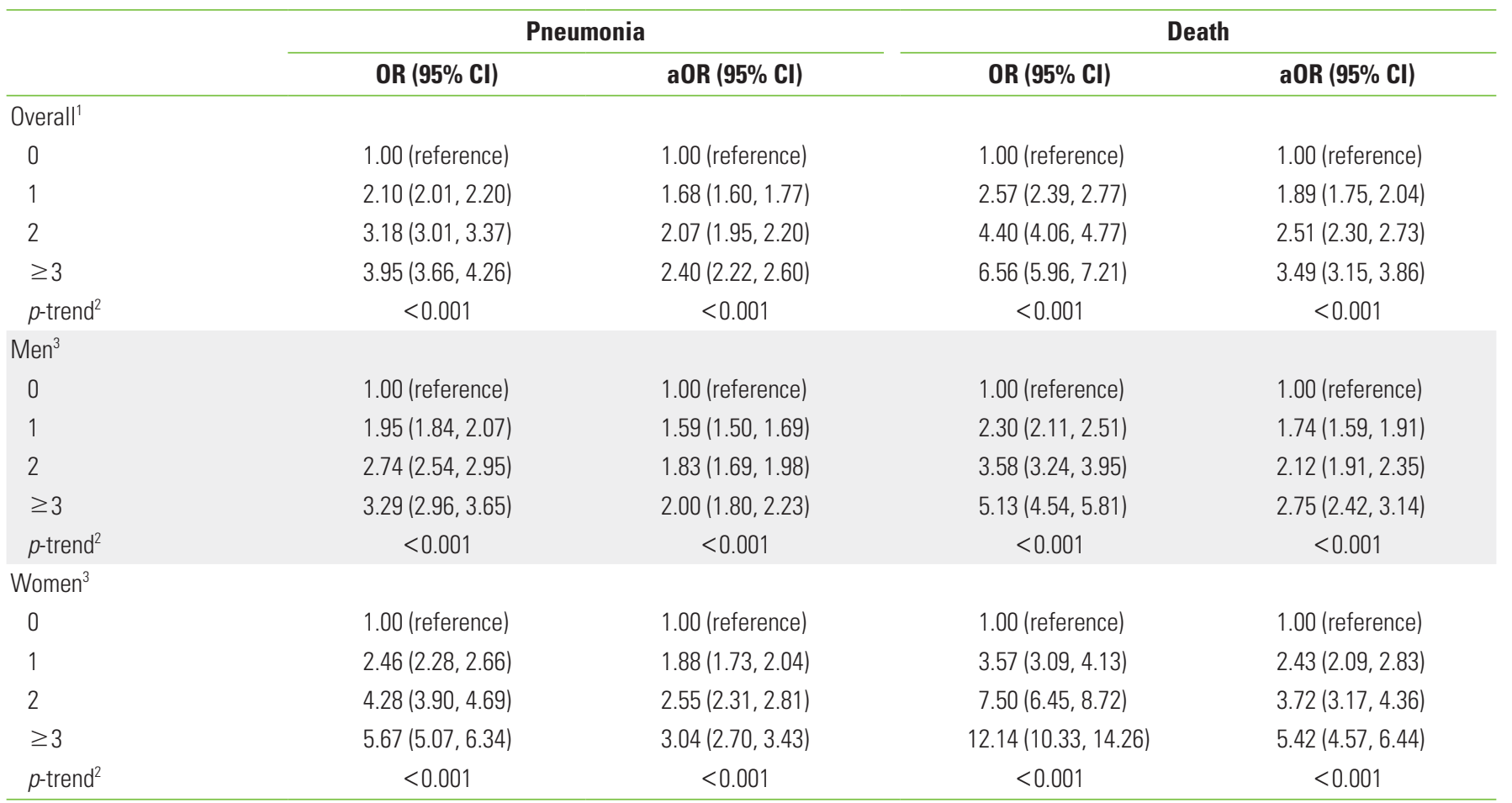

$\mathrm{OR}$, odds ratio; $\mathrm{Cl}$, confidence interval; aOR, adjusted odds ratio.

${ }^{1}$ Adjusted analysis by age, sex, and smoking status.

${ }^{2}$ Test for trend of OR.

${ }^{3}$ Adjusted analysis by age and smoking status.

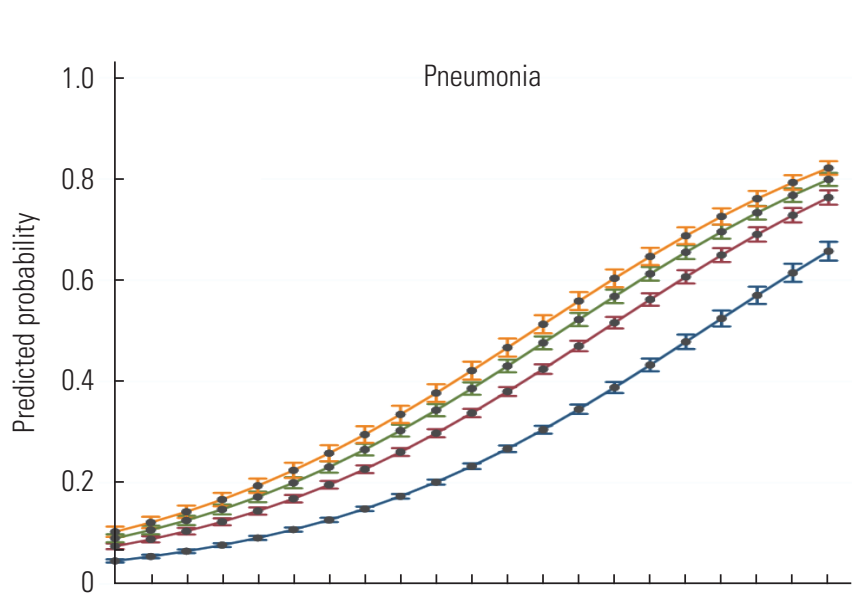

5101520253035404550556065707580859095100 Age (y)

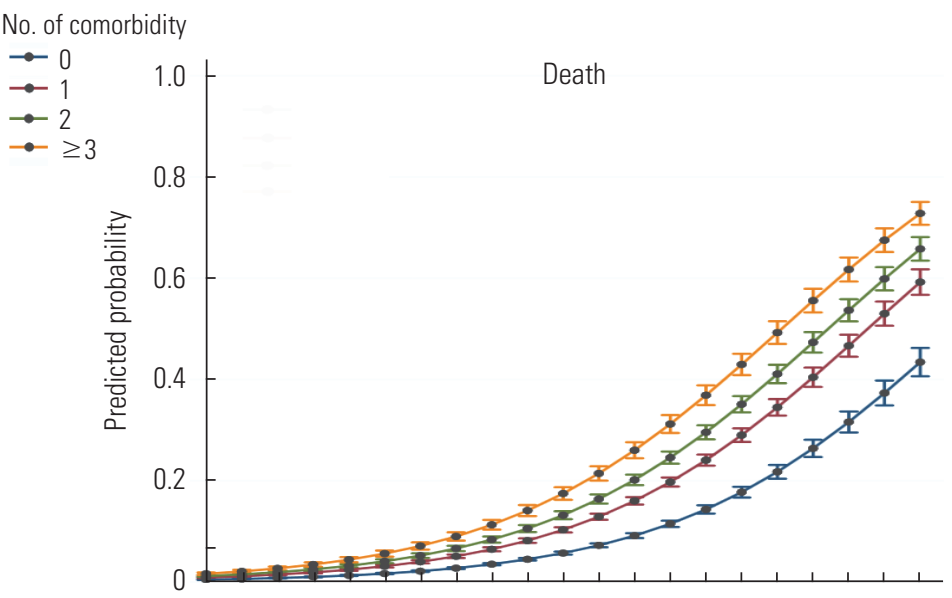

A
5101520253035404550556065707580859095100 Age (y)

Figure 1. Marginal effects of age (in years) and number of comorbidities on the probabilities of (A) pneumonia or (B) death in the Mexican population with coronavirus disease 2019 (COVID-19).

with COVID-19. Likewise, in the study from Wuhan, these conditions were associated with the presence of pneumonia [2]. Furthermore, the Centers for Disease Control and Prevention in the United States reported that people with serious medical conditions such as asthma (moderate to severe), COPD, diabetes, CVDs, kidney diseases, severe obesity, immunosuppression, and liver diseases have a greater probability of developing severe forms of COVID-19, including pneumonia [15]. It 
has been postulated that the development and severity of pneumonia may be influenced by the use of antihypertensive medication, commonly prescribed to patients with HBP and diabetes. These medications may lead to elevated lung tissue concentrations of angiotensin-converting enzyme 2, which acts as the receptor for the entry of SARS-CoV-2 $[16,17]$. However, other authors have reported that elevated angiotensinconverting enzyme 2 levels are not associated with an increased risk of pneumonia [18]. This suggests the need for further study of the influence of chronic conditions on the development of COVID-19.

Regarding multimorbidity and pneumonia in patients with COVID-19, the probability of developing pneumonia was found to increase as the number of chronic conditions increased. COVID-19 patients with comorbidities have been reported to exhibit a worse response to treatment than patients without comorbidities [19]. HBP and respiratory and CVDs are associated with a relatively severe presentation of COVID-19, including the development of pneumonia [20-22]. Likewise, greater patient age is associated with the development of pneumonia and the severe presentation of COVID-19 [23]. The presence of multimorbidity among adults (particularly older adults) impacts the physical and mental health of this group, particularly in lowincome and middle-income countries [24]. This affects the response capacity to treatment in these patients.

An association was found between the presence of chronic conditions and death in patients with COVID-19. In China, a higher frequency of COVID-19 infection and a greater lethality of the disease have been reported among patients with HBP $[4,13,20,24]$. Diabetes has also been described as one of the most common chronic conditions in patients with COVID-19, especially among those in the intensive care unit or with severe forms of the disease $[12,19,25]$. Obesity is another chronic condition associated with increased mortality risk due to challenges in the management of obese patients in relation to positioning, mobilization, and intubation [26,27]. Regarding immunosuppression, the host immunological response to SARSCoV-2 infection and its relationship with the pathophysiology and prognosis of the disease is still under study $[28,29]$. It has been reported that patients with COPD have an increased risk of developing severe forms of illness, possibly due to alterations in the inflammatory response, immunological and microbiome imbalances, and the use of corticosteroids, among other factors [30]. Chronic kidney disease has also been described as a chronic condition associated with a greater risk of severe manifestation of COVID-19 and death [8,31,32].

With respect to the relationship between multimorbidity and death in patients with COVID-19, an incrementally higher probability of death was observed among patients with more chronic conditions. The prevalence of multimorbidity increases with age [33]. In addition, it has been reported that older adults who have 2 or more comorbidities have a higher mortality rate than adults who do not $[33,34]$. The case series on COVID-19 published to date describe greater disease severity and a higher risk of death among older patients, particularly the most elderly $[11,14]$. In Mexico, the presence of multimorbidity in adults has been described as a predictor of quality of life and all-cause mortality [35]. Mexico has a significant burden of disease due to chronic diseases; in 2016, $80 \%$ of deaths were attributable to chronic conditions [6]. This high rate of deaths due to chronic diseases corresponds to the high prevalence of chronic conditions in the Mexican population, among which $25.5 \%$ of individuals have HBP [7], and $28 \%$ of adults are obese [6]. Given that multimorbidity can increase the risk of death due to COVID-19, in countries like Mexico, which have a high burden of disease due to these conditions, it is necessary to develop strategies to mitigate the spread of this disease in these population subgroups to decrease the impact of COVID-19 on health systems.

This study was not without limitations. The data analyzed were secondary in nature, and the accuracy of the data therefore, cannot be guaranteed. Additionally, the cases analyzed included only patients diagnosed with COVID-19 via RT-PCR, and thus, false-negative results of the RT-PCR test would not have been included in the analysis. In addition, bias may have been introduced insofar as the process of obtaining and handling of the sample influenced the results of the diagnostic test. Another possible source of bias stems from the fact that patients with asymptomatic or mildly symptomatic COVID-19 who did not seek medical attention would not have been included among the cases analyzed. Despite the limitations inherent to the information source, the use of a large dataset that includes all COVID-19 cases identified with molecular diagnostic tests and collected officially by the government of Mexico is useful for the initial study of the relationship between multimorbidity and COVID-19, bearing in mind the high burden of disease due to chronic conditions in Mexico.

In conclusion, several chronic conditions are associated with the development of pneumonia and death in Mexican patients 
with COVID-19. Additionally, an increase in the number of simultaneous chronic conditions was found to be associated with increased risk of pneumonia and death among these patients. These findings may be useful in the effort by decisionmakers to develop strategies to prevent COVID-19 in vulnerable subgroups, such as people with comorbidities. According to reports from different sources, patients with chronic conditions have a greater risk of COVID-19 than patients without such conditions. Hence, additional research is necessary to understand and deepen the study of the pathophysiological processes that determine this association, and this research is particularly important due to the high burden of chronic disease in various Latin American countries, including Mexico.

\section{CONFLICT OF INTEREST}

The authors have no conflicts of interest associated with the material presented in this paper.

\section{FUNDING}

None.

\section{ACKNOWLEDGEMENTS}

We would like to acknowledge the Secretaría de Salud de México for making public the necessary databases for the conduct of this study.

\section{AUTHOR CONTRIBUTIONS}

Conceptualization: AHV, DA. Data curation: AHV, RVF. Formal analysis: AHV, RVF. Funding acquisition: None. Methodology: AHV. Visualization: AHV. Writing - original draft: GBQ, DA, RVF, AHV. Writing - review \& editing: GBQ, DA, RVF, AHV.

\section{ORCID}

Akram Hernández-Vásquez https://orcid.org/0000-00031431-2526

Diego Azañedo https://orcid.org/0000-0003-1375-8788

Rodrigo Vargas-Fernández https://orcid.org/0000-00023310-8689

Guido Bendezu-Quispe https://orcid.org/0000-0002-51400843

\section{REFERENCES}

1. Coronavirus Resource Center, Johns Hopkins University. Maps \& trends [cited 2020 May 1]. Available from: https://coronavirus.jhu.edu/map.html.

2. Wang D, Hu B, Hu C, Zhu F, Liu X, Zhang J, et al. Clinical characteristics of 138 hospitalized patients with 2019 novel coronavirus-infected pneumonia in Wuhan, China. JAMA 2020; 323(11):1061-1069.

3. Huang C, Wang Y, Li X, Ren L, Zhao J, Hu Y, et al. Clinical features of patients infected with 2019 novel coronavirus in Wuhan, China. Lancet 2020;395(10223):497-506.

4. Fang L, Karakiulakis $G$, Roth M. Are patients with hypertension and diabetes mellitus at increased risk for COVID-19 infection? Lancet Respir Med 2020;8(4):e21.

5. Varga Z, Flammer AJ, Steiger P, Haberecker M, Andermatt R, Zinkernagel AS, et al. Endothelial cell infection and endotheliitis in COVID-19. Lancet 2020;395(10234):1417-1418.

6. World Health Organization. Noncommunicable diseases (NCD) country profiles 2018 [cited 2020 May 1]. Available from: https:// apps.who.int/iris/handle/10665/274512.

7. Nonato IC, Barrera LH, Pedroza A, Medina C, Barquera S. Hypertension in Mexican adults: prevalence, diagnosis and type of treatment. Ensanut MC 2016. Salud Publica Mex 2018;60(3): 233-243 (Spanish).

8. Guan WJ, Liang WH, Zhao Y, Liang HR, Chen ZS, Li YM, et al. Comorbidity and its impact on 1590 patients with COVID-19 in China: a nationwide analysis. Eur Respir J 2020;55(5):2000547.

9. Henry BM, Lippi G. Chronic kidney disease is associated with severe coronavirus disease 2019 (COVID-19) infection. Int Urol Nephrol 2020;52(6):1193-1194.

10. Boettler T, Newsome PN, Mondelli MU, Maticic M, Cordero E, Cornberg $\mathrm{M}$, et al. Care of patients with liver disease during the COVID-19 pandemic: EASL-ESCMID position paper. JHEP Rep 2020;2(3):100113.

11. Zhou F, Yu T, Du R, Fan G, Liu Y, Liu Z, et al. Clinical course and risk factors for mortality of adult inpatients with COVID-19 in Wuhan, China: a retrospective cohort study. Lancet 2020; 395(10229):1054-1062.

12. Shi Y, Yu X, Zhao H, Wang H, Zhao R, Sheng J. Host susceptibility to severe COVID-19 and establishment of a host risk score: findings of 487 cases outside Wuhan. Crit Care 2020;24(1):108.

13. Yang J, Zheng Y, Gou X, Pu K, Chen Z, Guo Q, et al. Prevalence of comorbidities and its effects in patients infected with SARSCoV-2: a systematic review and meta-analysis. Int J Infect Dis 
Journal of

2020;94:91-95.

14. Chen T, Wu D, Chen H, Yan W, Yang D, Chen G, et al. Clinical characteristics of 113 deceased patients with coronavirus disease 2019: retrospective study. BMJ 2020;368:m1091.

15. Centers for Disease Control and Prevention. Coronavirus disease 2019 (COVID-19) [cited 2020 Apr 30]. Available from: https:// www.cdc.gov/coronavirus/2019-ncov/need-extra-precautions/ groups-at-higher-risk.html.

16. Sun ML, Yang JM, Sun YP, Su GH. Inhibitors of RAS might be a good choice for the therapy of COVID-19 pneumonia. Zhonghua Jie He He Hu Xi Za Zhi 2020;43(3):219-222 (Chinese).

17. Diaz JH. Hypothesis: angiotensin-converting enzyme inhibitors and angiotensin receptor blockers may increase the risk of severe COVID-19. J Travel Med 2020;27(3):taaa041.

18. Bravi F, Flacco ME, Carradori T, Volta CA, Cosenza G, De Togni A, et al. Predictors of severe or lethal COVID-19, including angiotensin converting enzyme inhibitors and angiotensin II receptor blockers, in a sample of infected Italian citizens. PLoS One 2020;15(6):e0235248.

19. Mo P, Xing Y, Xiao Y, Deng L, Zhao Q, Wang H, et al. Clinical characteristics of refractory COVID-19 pneumonia in Wuhan, China. Clin Infect Dis 2020:ciaa270.

20. Yang X, Yu Y, Xu J, Shu H, Xia J, Liu H, et al. Clinical course and outcomes of critically ill patients with SARS-CoV-2 pneumonia in Wuhan, China: a single-centered, retrospective, observational study. Lancet Respir Med 2020;8(5):475-481.

21. Wu C, Chen X, Cai Y, Xia J, Zhou X, Xu S, et al. Risk factors associated with acute respiratory distress syndrome and death in patients with coronavirus disease 2019 pneumonia in Wuhan, China. JAMA Intern Med 2020:e200994.

22. Li K, Wu J, Wu F, Guo D, Chen L, Fang Z, et al. The clinical and chest $\mathrm{CT}$ features associated with severe and critical COVID-19 pneumonia. Invest Radiol 2020;55(6):327-331.

23. Liu W, Tao ZW, Wang L, Yuan ML, Liu K, Zhou L, et al. Analysis of factors associated with disease outcomes in hospitalized patients with 2019 novel coronavirus disease. Chin Med J (Engl) 2020;133(9):1032-1038.

24. Arokiasamy P, Uttamacharya U, Jain K, Biritwum RB, Yawson
$A E$, Wu F, et al. The impact of multimorbidity on adult physical and mental health in low- and middle-income countries: what does the study on global ageing and adult health (SAGE) reveal? BMC Med 2015;13:178.

25. Patel $A B$, Verma A. COVID-19 and angiotensin-converting enzyme inhibitors and angiotensin receptor blockers: what is the evidence? JAMA 2020;323(18):1769-1770.

26. Guan WJ, Ni ZY, Hu Y, Liang WH, Ou CQ, He JX, et al. Clinical characteristics of coronavirus disease 2019 in China. N Engl J Med 2020;382(18):1708-1720.

27. Dietz W, Santos-Burgoa C. Obesity and its implications for COVID-19 mortality. Obesity (Silver Spring) 2020;28(6):1005.

28. Ryan DH, Ravussin E, Heymsfield S. COVID 19 and the patient with obesity - the editors speak out. Obesity (Silver Spring) 2020;28(5):847.

29. D'Antiga L. Coronaviruses and immunosuppressed patients: the facts during the third epidemic. Liver Transpl 2020;26(6): 832-834.

30. Siddiqi HK, Mehra MR. COVID-19 illness in native and immunosuppressed states: a clinical-therapeutic staging proposal. J Heart Lung Transplant 2020;39(5):405-407.

31. Lippi G, Henry BM. Chronic obstructive pulmonary disease is associated with severe coronavirus disease 2019 (COVID-19). Respir Med 2020;167:105941.

32. Cheng Y, Luo R, Wang K, Zhang M, Wang Z, Dong L, et al. Kidney disease is associated with in-hospital death of patients with COVID-19. Kidney Int 2020;97(5):829-838.

33. Nunes BP, Flores TR, Mielke GI, Thumé E, Facchini LA. Multimorbidity and mortality in older adults: a systematic review and meta-analysis. Arch Gerontol Geriatr 2016;67:130-138.

34. Landi F, Liperoti R, Russo A, Capoluongo E, Barillaro C, Pahor M, et al. Disability, more than multimorbidity, was predictive of mortality among older persons aged 80 years and older. J Clin Epidemiol 2010;63(7):752-759.

35. Rivera-Almaraz A, Manrique-Espinoza B, Ávila-Funes JA, Chatterji $S$, Naidoo N, Kowal $P$, et al. Disability, quality of life and all-cause mortality in older Mexican adults: association with multimorbidity and frailty. BMC Geriatr 2018;18(1):236. 